\title{
FATORES QUE INTERFEREM NO DESENVOLVIMENTO DO TURISMO SUSTENTÁVEL NO ESPAÇO RURAL DO ROTEIRO TURÍSTICO VALE DOS VINHEDOS, DE BENTO GONÇALVES/RS - BRASIL
}

FACTORS INVOLVED IN THE DEVELOPMENT OF SUSTAINABLE TOURISM OF THE ROUTE VALE DOS VINHEDOS, DE BENTO GONÇALVES/RS - BRASIL

\begin{abstract}
Sergio Foletto
Mestre em Turismo (Universidade de Caxias do Sul/Brasil). Secretário da Associação BentoGonçalvense de Proteção ao Ambiente Natural (Bento Gonçalves/Brasil) E-mail:sergio.foletto@yahoo.com.br.
\end{abstract}

Eurico de Oliveira Santos

Doutor em Ciências Agropecuárias

e Recursos Naturais (Universidade

Autônoma do Estado do México).

Professor do Programa de Pós-Graduação em

Turismo da Universidade de Caxias do Sul.E-

\section{Humberto Thomé-Ortiz}

Doutor em Ciências Agrárias (Universidade

Autônoma do Estado do México). Professor

do Programa de Pós-Graduação em Turismo da Universidade de Caxias do Sul. E-mail:

humbertothome@hotmail.com.

Noe Antonio Aguirre González

Mestre em Ciências Agropecuárias e Recursos

Naturais (Universidade Autônoma do Estado do

México).E-mail: geog_naguirre@yahoo.com.mx. 


\section{RESUMO}

O presente trabalho analisa o desenvolvimento do turismo no espaço rural das propriedades do Vale dos Vinhedos, em Bento Gonçalves, Estado do Rio Grande do Sul, Brasil. Nele, descrevem-se as características da região, seus vinhedos, estabelecimentos e vinícolas responsáveis pela conquista da $1^{\text {a }}$ Denominação de Origem Vale dos Vinhedos do Brasil. O roteiro turístico caracteriza-se pela beleza da paisagem, pelo espírito empreendedor dos produtores rurais, pela valorização do patrimônio e da cultura. O problema desta pesquisa é saber se o turismo rural e o enoturismo são alternativas econômicas para os produtores rurais do Vale dos Vinhedos. O objetivo geral consiste em analisar as potencialidades do Vale e identificar os fatores que interferem no desenvolvimento do turismo. A metodologia utilizada baseia-se em pesquisa de campo, observação e pesquisa documental. Para tanto, foram realizadas entrevistas com dois produtores rurais, quatro proprietários de estabelecimentos vinícolas e um representante da Associação de Produtores de Vinhos Finos do Vale dos Vinhedos. A pesquisa qualitativa consistiu na descrição pormenorizada das observações e das entrevistas realizadas. Os resultados mostram que o empreendedorismo dos produtores rurais é um fator importante para o desenvolvimento econômico, identificando-se aspectos merecedores da atenção dos poderes públicos e empreendedores do turismo.

Palavras-chave: Turismo no espaço rural. Desenvolvimento vitivinícola. Enoturismo. Vale dos Vinhedos.

\section{RESUMEN}

The present work analyzes the development of tourism in the rural area of Vale dos Vinhedos properties, in Bento Gonçalves, State of Rio Grande do Sul, Brazil. It describes the characteristics of the region, its vineyards, establishments and wineries responsible for the conquest of the 1st Denomination of Origin Vale dos Vinhedos do Brasil. The tourist route is characterized by the beauty of the landscape, the enterprising spirit of the rural producers, the valuation of heritage and culture. The problem with this research is whether rural tourism and wine tourism are economic alternatives for rural producers in the Vale dos Vinhedos. The overall objective is to analyze the potential of the Valley and identify the factors that interfere in the development of tourism. The methodology used is based on field research, observation and documentary research. For that, interviews were conducted with two farmers, four owners of wineries and one representative of the Association of Fine Wine Producers of Vale dos Vinhedos. The qualitative research consisted of a detailed description of the observations and interviews. The results show that the entrepreneurship of the rural producers is an important factor for the economic development, identifying aspects deserving the attention of the public authorities and entrepreneurs of the tourism.

Keywords: Rural tourism. Wine development. Wine tourism. Vale dos Vinhedos. 


\section{INTRODUÇÃO}

Estuda-se o desenvolvimento do turismo no espaço rural das propriedades do Vale dos Vinhedos, no município de Bento Gonçalves/RS, destacando-se as características do seu território e sua paisagem, o empreendedorismo dos produtores rurais na modernização de seus vinhedos e a elaboração dos vinhos e espumantes. O Vale dos Vinhedos caracteriza-se, também, pela valorização do patrimônio, da cultura, das tradições e costumes herdados dos imigrantes provenientes da Itália.

O município de Bento Gonçalves tornou-se um dos municípios mais prósperos e desenvolvidos, graças, principalmente, à atividade vitivinícola - cultura básica desenvolvida pelas famílias estabelecidas nesse espaço rural - e pela sua relação, no tempo, com a atividade turística, especialmente nas últimas décadas, quando o crescimento do setor vem ganhando proporções significativas, sendo reconhecido como a Capital Brasileira da Uva e do Vinho.

Ao apresentar os roteiros turísticos de Bento Gonçalves, Luchese (2002) assim escreve:

Num vale mágico que corre por entre as divisas de Bento Gonçalves, Garibaldi e Monte Belo do Sul, numa região privilegiada por um clima consagrado ao cultivo da vinha, as mais finas castas desenvolveram-se naturalmente, e o lugar tornou-se o Vale dos Vinhedos. É caracterizado por suas cantinas familiares de vinhedos próprios, onde é possível conhecer todo o processo de produção do vinho e as marcas culturais deixadas pela imigração italiana. (LUCHESE, 2002, p. 185).

O roteiro turístico Vale dos Vinhedos tem a cultura do vinho incorporada na vida dos produtores rurais como um patrimônio comunitário do qual todos são partícipes e agentes. O vinho é cultura; é estilo de vida e componente de uma civilização. Onde existe a cultura do vinho estão presentes: a boa gastronomia, as artes, o artesanato, a música, a alegria, a religiosidade, a solidariedade, a vocação pelo trabalho e pelo progresso.

Corrobora com esse pensamento Ubaldo (1999) ao afirmar:

É oportuno notar que o vinho sempre esteve ligado aos povos de civilização mais adiantada em todos os tempos. Assim foi com os egípcios, mesopotâmicos, hebreus, gregos e latinos. Assim continua a ser nos dias de hoje. Não seria desapropriado afirmarse que o nível cultural de um povo poderia ser avaliado pela quantidade e qualidade do vinho que produz e/ou consome. (UBALDO, 1999, p. 84-85).

Sob todos os aspectos, o vinho é um produto turístico diferenciado, assegurando um permanente fluxo de turistas, atraídos pelo charme, pelo aroma e pela emoção de uma bebida histórica e milenar.

O vinho constitui-se em um dos elementos mais importantes de desenvolvimento regional, impulsionando os viticultores para a atividade principal do Vale dos Vinhedos, que é a atividade enoturística. 
É desta forma que o vinho, o turismo e o ambiente natural se unem, tendo por base a tradição cultural, o trabalho, as características da natureza e a dedicação dos proprietários rurais e empreendedores ao setor da vitivinicultura, sempre voltados para novas conquistas, contribuindo para o desenvolvimento turístico.

De Paris (1999) apresentou, em sucessão cronológica, dados importantes que marcaram a história local, a partir do processo imigratório, sem desconhecer o espaço geográfico, registrando que:

O distrito Vale dos Vinhedos foi criado em 17 de agosto de 1990, pela Lei Municipal nº 1805. A área do novo distrito foi desmembrada de Monte Belo e da sede do Município. Os primeiros imigrantes italianos chegaram ao atual Vale dos Vinhedos em janeiro de 1877, vindos do Tirol. (DE PARIS, 1999, p. 226).

Acrescenta De Paris (1999) que "o distrito recebeu este nome devido aos imensos parreirais, pela sua posição geográfica, seu solo e sua altitude”. O desenvolvimento e a prosperidade da comunidade do Vale dos Vinhedos tiveram como base a cultura, o trabalho, o espírito empreendedor, as características da natureza e a dedicação dos agricultores ao setor da vitivinicultura.

Com as pesquisas realizadas no setor da vitivinicultura, tendo a Embrapa Uva e Vinho² uma parceria junto à Aprovale ${ }^{3}$ e outras instituições afins, ocorreu a modernização dos vinhedos e a elaboração de vinhos conquistando a $1^{a}$ Indicação de Procedência e a $1^{a}$ Denominação de Origem do Brasil.

A Lei nº 9279 (Brasil, 1996), atualizada pela lei n 10.196 (Brasil, 2001), prevê as designações para a Indicação de Procedência e a Denominação de Origem:

Art. 177 - Considera-se indicação de procedência o nome geográfico de país, cidade, região ou localidade do seu território, que se tenha tornado conhecido como centro de extração, produção ou fabricação de determinado produto ou de prestação de determinado serviço (BRASIL, 1996).

Art. 178 - Considera-se denominação de origem o nome geográfico de país, cidade, região ou localidade de seu território, que designe produto ou serviço cujos qualidades ou características se devam exclusivamente ou essencialmente ao meio geográfico, incluídos fatores naturais e humanos (BRASIL, 1996).

\footnotetext{
${ }^{1}$ Administrativamente, Bento Gonçalves tinha o seu território divido em seis distritos. Cada distrito tinha um subintendente que exercia as funções delegadas pelo intendente, bem como as funções de autoridade policial, conforme divisão administrativa: 1924 a 1928. (DE PARIS, 1999, p. 88).

2 Empresa Brasileira de Pesquisa Agropecuária, Centro Nacional de Pesquisa de Uva e Vinho, vinculada ao Ministério da Agricultura e do Abastecimento. A Unicidade de Bento Gonçalves executa projetos na área de viticultura, enologia e fruticultura.

${ }^{3}$ Associação dos Produtores de Vinhos Finos do Vale dos Vinhedos.
} 


\title{
Gestãoe \\ Desenvolvimento
}

O processo de Indicação de Procedência Vale dos Vinhedos, conforme pesquisa desenvolvida por Fernández (2012):

\begin{abstract}
Trouxe melhorias na região, perceptíveis para os pequenos produtores, das quais podem ser citadas a segurança na região, o crescimento do enoturismo e, consequentemente, maior arrecadação para a região e valorização do produto tanto pelas vinícolas como pelos consumidores diretos (FERNÁNDEZ, 2012, p. 76-77).
\end{abstract}

O enoturismo do Vale dos Vinhedos foi estruturado pelo pioneirismo e empreendedorismo dos produtores rurais que, motivados pelo exemplo das primeiras gerações, dedicaram-se ao cuiltivo das videiras, produzindo vinhos de qualidade, atraindo sempre maior fluxo de turistas.

Várias gerações passaram desde a chegada dos primeiros imigrantes e muitas famílias que ali se instalaram continuam trabalhando e desenvolvendo a cultura vitivinícola, produzindo vinhos de qualidade, reconhecidos nacional e internacionalmente.

O roteiro turístico Vale dos Vinhedos localiza-se no município de Bento Gonçalves, no Estado do Rio Grande do Sul, na Encosta Superior do Nordeste - Serra Gaúcha, conforme se observa nos mapas.

A vitivinicultura é uma atividade dos produtores rurais do Vale dos Vinhedos que é desenvolvida, viabilizando economicamente as pequenas propriedades com a produção de uvas e elaboração de vinhos, sucos e espumantes.

Em 1995, um grupo de produtores se reuniu com o propósito de fundar a Associação dos Produtores de Vinhos Finos do Vale dos Vinhe-
Figura 1 - Mapa da localização do roteiro turístico Vale dos Vinhedos

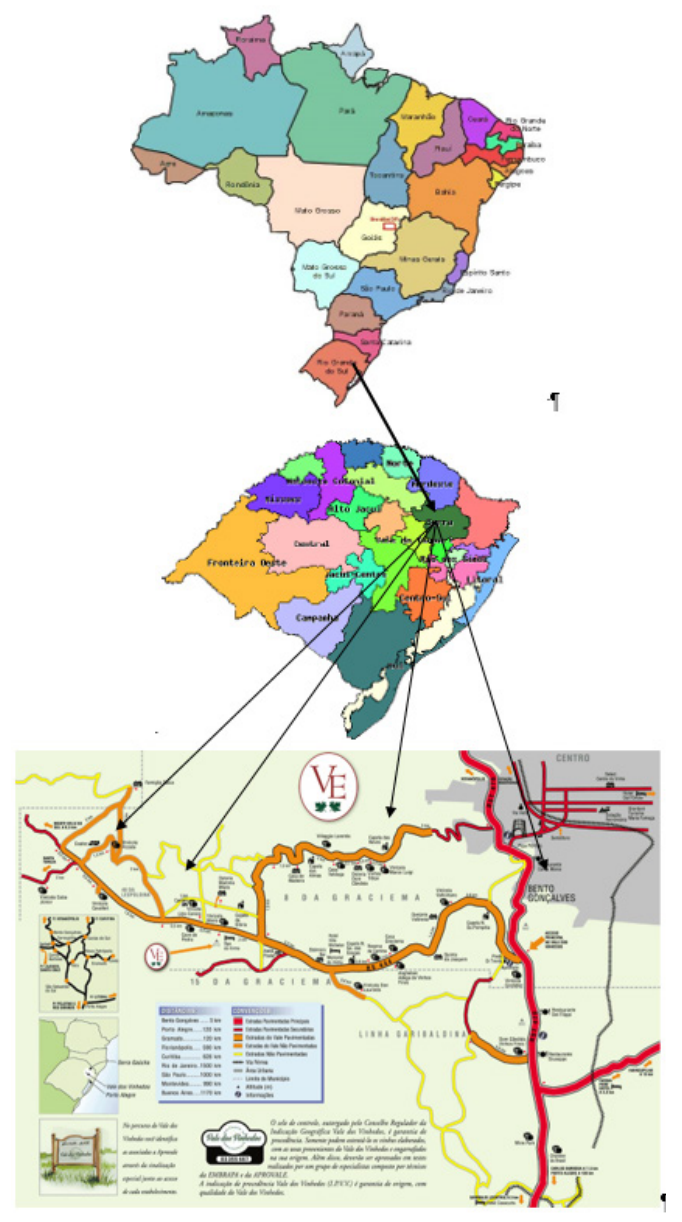

Fonte: Imagens disponíveis na Internet ${ }^{1}$

${ }^{1}$ Disponível em: <http://www.google.com.brr. Acesso em: 12 set. 2017. 
dos - APROVALE, com o objetivo de buscar a Indicação de Procedência e Denominação de Origem de seus vinhos e espumantes.

Hoje, é constituída por um total de 69 associados, sendo 27 associados produtores e 42 associados setoriais. Entre os associados setoriais, situam-se 4 hotéis, 5 pousadas, 4 artesanatos, 14 restaurantes e 15 com outras atividades.

O Vale dos Vinhedos conquistou a $1^{\text {a }}$ Indicação de Procedência em 22 de novembro de 2002 e a $1^{\text {a }}$ Denominação de Origem em 25 de setembro de 2012. A região demarcada abrange uma área de 72,45 km² em três municípios: 55\% Bento Gonçalves, 37\% Garibaldi e 8\% Monte Belo do Sul (APROVALE, 2014).

As inúmeras ações da APROVALE promoveram mudanças na conquista da Indicação de Procedência dos vinhos e espumantes elaborados pelos Estabelecimentos Vinícolas do Vale. Essas ações, segundo Falcade (2005):

Induziram a um certo desenvolvimento ao criarem algumas das condições necessárias ao aumento de renda e à melhoria das condições de vida. Isto foi verificado não somente junto aos envolvidos na agro-indústria do vinho, mas também àqueles que somente produzem a uva ou desenvolvem outras atividades (FALCADE, 2005, p. 47).

Além da Indicação de Procedência, graças aos parâmetros de qualidade aplicados pelas Vinícolas na elaboração de seus produtos, o Vale dos Vinhedos conquistou a primeira Denominação de Origem de vinhos e espumantes do Brasil, pelo Instituto Nacional de Propriedade Industrial - INPI.

Através do Projeto de Lei $n^{\circ}$ 44/2012, aprovado por unanimidade pela Assembléia Legislativa, que tornou-se Lei, o Vale dos Vinhedos foi declarado oficialmente Patrimônio Histórico e Cultural do Rio Grande do Sul.

Há grande expectativa quanto à manutenção do roteiro, dos atrativos e da qualidade de seus produtos, bem como quanto à infraestrutura e ao cumprimento da legislação ambiental para garantir o desenvolvimento do turismo.

De acordo com a NBR 15.401 (2006), a garantia de um turismo responsável deverá seguir os seguintes princípios: $1^{\circ}$ ) respeitar a legislação vigente em todos os níveis: federal, estadual e municipal; $2^{\circ}$ ) garantir os direitos das populações locais, promovendo ações de responsabilidade social, ambiental e de equidade econômica; $3^{\circ}$ ) conservar o seu ambiente natural e sua biodiversidade, em todas as fases de implantação e operação de empreendimentos, adotando práticas de mínimo impacto sobre o ambiente natural; $4^{\circ}$ ) considerar o patrimônio cultural e valores locais; $5^{\circ}$ ) estimular o desenvolvimento social e econômico dos destinos turísticos; $6^{\circ}$ ) garantir a qualidade dos produtos, processos e atitudes; e $7^{\circ}$ ) estabelecer 0 planejamento e a gestão responsáveis. (NBR 15.401, 2006). 
Neste sentido, estes princípios devem estar presentes no desenvolvimento da atividade turística, garantindo sua sustentabilidade, minimizando impactos na área ambiental, sociocultural e econômica.

\section{REFERENCIAL TEÓRICO}

O tema deste trabalho está voltado para o desenvolvimento do turismo no espaço rural do Vale dos Vinhedos. Busca identificar características do roteiro e os fatores ou potencialidades decorrentes do espírito empreendedor dos produtores rurais, que garantiram inúmeras e importantes conquistas, com vistas ao desenvolvimento econômico, social, ambiental e cultural. Buscou-se, também, identificar aspectos e problemas que merecem a atenção e ações urgentes por parte da administração pública e dos empreendedores do turismo do Vale.

A necessidade de se consolidar o espaço rural do Vale dos Vinhedos como roteiro turístico que atenda à expectativa do fluxo sempre maior de turistas exigirá estratégias de planejamento integradas entre os três municípios: Bento Gonçalves, Garibaldi e Monte Belo do Sul, com a participação dos proprietários rurais e empreendedores da localidade.

Para atender ao tema proposto e procurar uma resposta ao problema deste projeto, que é saber se o turismo no espaço rural do Vale dos Vinhedos pode ser considerado uma alternativa econômica e se a vocação para a vitivinicultura e o enoturismo mostram o potencial e o espírito empreendedor dos vitivinicultores, é importante a contribuição de estudos e pesquisas.

\subsection{PLANO DIRETOR DE DESENVOLVIMENTO INTEGRADO}

Para atender a Dispositivos Constitucionais, foi sancionada a Lei n 10.257 de 10 de Julho de 2001, que regulamenta os artigos 182 e 183 da Constituição Federal, estabelece diretrizes gerais da política urbana e dá outras providências, determinando prazos para que Estados e Municípios elaborem seus Planos Diretores.

Para garantir o turismo no espaço rural do Vale dos Vinhedos, com base num diagnóstico da situação do município de Bento Gonçalves, foi elaborado um Projeto de lei, transformando-se na Lei Complementar $n^{\circ}$ 103, de 26 de outubro de 2006, que instituiu o novo Plano Diretor de Desenvolvimento Integrado do Município que, em seu Anexo $1^{\circ}$, estabelece as principais diretrizes para o desenvolvimento e a sustentabilidade da atividade turística, principalmente quanto à vocação e à preservação ambiental, de valores, do patrimônio e da cultura, presentes em cada território que forma os roteiros turísticos e que se constituem no principal atrativo para os visitantes (BENTO GONÇALVES, 2006). 
É de fundamental importância a aplicação desta lei para a estruturação específica do espaço rural, conforme consta no Artigo 162, referindo-se ao Modelo Espacial Básico como "o conjunto de regulamentos de ocupação e uso do solo da área rural, com predominância agrícola, turística, agroindustrial e de conservação".

O Artigo 163 do Plano Diretor estabelece que "para efeito da aplicação desta lei, são criadas as seguintes zonas de uso do solo rural: I - Distrito do Vale dos Vinhedos: Área de Proteção à Paisagem Vale dos Vinhedos (APPVALE)".

É importante salientar que o Plano Diretor do município de Bento Gonçalves preocupou-se em integrar o desenvolvimento urbano e rural, contemplando a vocação de cada área, conforme consta nos artigos que seguem, específicos para o Vale dos Vinhedos.

Assim estabelece o Artigo 164: "O Distrito do Vale dos Vinhedos (APPVALE) tem como vocação natural consolidada a vitivinicultura, cuja cultura, ocupação do solo e paisagem ficam protegidas na forma desta lei”.

No Artigo 165, "ficam estabelecidas como normas de proteção do Vale dos Vinhedos: a totalidade da área, tendo como elementos protegidos os vinhedos e a linha do horizonte". No item III estabelece-se as condições de proteção:

As áreas hoje destinadas à vitivinicultura ficam protegidas de forma permanente e somente poderão ser utilizadas para outros fins que excluam a viticultura e substituídas por novas áreas de cultivo dessa cultura na mesma propriedade, bem como será incentivado o desenvolvimento de novas áreas de cultivo (BENTO GONÇALVES, 2006).

O Artigo 166 diz que "serão permitidos usos do solo temporários e simultâneos à cultura principal que é a viticultura", e o Artigo 167 estabelece que "a linha do horizonte está protegida de forma que nenhuma edificação poderá seccioná-la, observada desde qualquer ponto da via pública da qual a propriedade tem acesso" (BENTO GONÇALVES, 2006).

O Plano Diretor, no artigo 246, referente à avaliação de impactos decorrentes da implantação de projetos de desenvolvimento, estabelece que essa avaliação será procedida através de indicadores qualitativos e quantitativos em quatro instâncias: impacto na paisagem, impacto no ambiente, impacto na estrutura funcional e impacto no desenvolvimento econômico e turístico.

Para a consolidação e a garantia de crescimento da atividade turística no Vale dos Vinhedos, o Plano Diretor de Desenvolvimento Integrado do município constitui-se base fundamental, extremamente importante para o destino turístico neste espaço rural.

O Plano estabelece uma diretriz fundamental na busca permanente do desenvolvimento econômico, social e de preservação do meio ambiente, integrando o rural e o urbano, permitindo que o turismo rural do Vale dos Vinhedos mantenha suas tradições, sua cultura e outras características de sua realidade enquanto espaço 
diferenciado, onde, além da atividade voltada para a agricultura, principalmente com a produção de uvas em seus vinhedos, desenvolvem-se estabelecimentos vinícolas, artesanatos, hotéis, pousadas e restaurantes.

\subsection{DESENVOLVIMENTO DO TURISMO RURAL}

Com relação ao desenvolvimento do Turismo Rural, Santos (2004) considera o agroturismo e turismo rural como uma alternativa participativa para o desenvolvimento regional e local e que o espaço rural tende a ser mais valorizado.

Segundo Santos (2004):

O agroturismo e o turismo rural em uma propriedade rural são possíveis desde que os proprietários diversifiquem suas atividades e valorizem apropriadamente sua produção. O agroturismo e o turismo rural são importantes na cultura rural enquanto atividades econômicas, pois constituem um fator de sobrevivência para o desenvolvimento da comunidade local (SANTOS, 2004, p. 32-33).

Acrescenta, ainda, que "nos países desenvovidos, as regiões que geram mais empregos não são as regiões essencialmente urbanas, nem essencialmente rurais, e sim aquelas onde essa ligação entre os espaços urbanos e rurais é mais intensa" (SANTOS, 2004, p. 31-32).

Referindo-se à emergência de uma nova ruralidade no Brasil, Wanderley (2000) afirma que:

Nas sociedades modernas, o desenvolvimento dos espaços rurais dependerá, não apenas do dinamismo do setor agrícola, porém, cada vez mais, da sua capacidade de atrair outras atividades econômicas e outros interesses sociais e de realizar uma profunda “ressignificação” de suas próprias funções sociais (WANDERLEY, 2000, p. 87-145).

No mesmo documento, segundo Wanderley (2000), há uma nova ruralidade nas sociedades modernas avançadas, onde as regiões rurais, carregadas de história, de tradições, forjadas pelo trabalho de gerações de homens e de mulheres, possuem um rico patrimônio e uma identidade cultural forte, sendo a cultura local fonte de atividades e um fator de desenvolvimento. As novas e múltiplas faces do rural não podem ser vistas como obra acabada, pois está em curso uma nova visão do rural, que propõe uma nova concepção das atividades produtivas, especialmente as ligadas à agropecuária, e uma nova concepção do "rural" como patrimônio a ser usufruído e a ser preservado.

O turismo é uma atividade econômica que auxilia no desenvolvimento das localidades onde ele ocorre, gerando emprego e renda para as comunidades e é considerado um fator econômico, social e político. Neste sentido, segundo Ignarra (2001): 
O turismo é uma atividade que tem grande importância no desenvolvimento socioeconômico. É uma atividade que possui grande poder de redistribuição espacial de renda, pois os principais emissores de turistas são países ricos e os receptores nem sempre são países ricos. É uma atividade que é intensa de mão-de-obra, podendo contribuir para o grande problema da sociedade moderna que é o desemprego estrutural. O turismo, ainda, tem papel muito importante na conservação do meio natural, pois em muitas regiões é a única atividade econômica que pode aliar geração de renda e emprego e conservação natural (IGNARRA, 2001, p. 61).

Referindo-se ao papel do poder público no desenvolvimento do turismo, o mesmo autor acrescenta: "o turismo é uma atividade econômica que tem no território, na paisagem, no patrimônio natural e cultural suas principais matérias-primas. Assim, não é possível produzir turismo sem que haja direta ou indiretamente uma participação do poder público" (IGNARRA, 2001, p. 125).

A ação da administração pública do município de Bento Gonçalves, através da lei do Plano Diretor de Planejamento Integrado, que estabeleceu as principais diretrizes para o desenvolvimento do turismo, a preservação da paisagem e dos vinhedos do território do Vale dos Vinhedos, é reforçada pelo pensamento de Ignarra (2001):

A ação governamental no turismo pode abranger várias atividades, como a promoção institucional da destinação, capacitação de recursos humanos, controle de uso e da conservação do patrimônio turístico, implantação e manutenção da estrutura básica e prestação de serviços de segurança pública (IGNARRA, 2001, p. 125).

Ao referir-se aos fundamentos da teoria de sistemas aplicados ao turismo, Beni (1998) destaca que:

O turismo é um eficiente meio para: 1. promover a difusão de informação sobre uma determinada região ou localidade, seus valores naturais, culturais e sociais; 2.abrir novas perspectivas sociais como resultado do desenvolvimento econômico e cultural da região (BENI, 1998, p. 41).

Para melhor visão do fenômeno do turismo, na análise teórica da atividade turística, Beni (1998) enfatiza a "perspectiva de produção e envolve uma pluralidade de empresas que atuam no setor, algumas das quais operam a transformação de matéria-prima em produto acabado, enquanto outras oferecem bens e serviços já existentes.” (BENI, 1998, p. 40).

Segundo Ruschmann (1997), "o turismo deve ser considerado como fator de desenvolvimento prioritário em todas as localidades nas quais ele se constitui a maior fonte de renda e a base da existência da maneira dos empreendimentos que dependem direta, ou indiretamente da atividade." (RUSCHMANN, 1997, p. 165). 
Ruschmann (1997), referindo-se aos agentes responsáveis pelo turismo e meio ambiente, enfatiza que:

O turismo nos espaços naturais não é apenas modismo de uma época e a opinião pública tem se conscientizado, cada vez mais, da necessidade de proteger o meio ambiente. Se pelo lado da demanda, a motivação "contato com a natureza" se torna cada vez mais intensa, a natureza intacta e protegida passa a ser um argumento comercial importante. Assim, o turismo de qualidade pode tornar-se economicamente viável, desde que associado à proteção dos espaços naturais e a excelência dos serviços e equipamentos oferecidos aos clientes. É preciso que o turismo e o meio ambiente encontrem um ponto de equilíbrio, a fim de que a atratividade dos recursos naturais não seja a causa da sua degradação. (RUSCHMANN, 1997, p. 27).

A dimensão ambiental no Vale dos Vinhedos constitui-se um dos fatores relevantes para o desenvolvimento das atividades do turismo.

Quanto a esse tema, Dias (2008) assim se manifesta:

Os princípios de sustentabilidade devem constituir o objetivo principal de qualquer espaço ou produto turístico, em qualquer de seus estágios evolutivos, e não circunscreverse exclusivamente às manifestações supostamente alternativas como o ecoturismo e o turismo rural. Na realidade, eles são mais necessários exatamente em espaços turísticos consolidados com maiores níveis de pressão ambiental, onde a estabilidade socioeconômica em grande medida dependerá da evolução positiva e equilibrada (sustentável, portanto) da atividade turística (DIAS, 2008, p. 69).

Brambatti (2002), referindo-se a Roteiros de Turismo e Patrimônio Histórico, reforça a ideia de preservação ambiental:

Os recentes investimentos em projetos de turismo rural buscam desenvolver uma sensibilidade mais profunda, com relação ao conjunto de possibilidades existentes no espaço rural e que podem ser aproveitadas, como a preservação do meio ambiente, a conservação do patrimônio histórico e cultural, a qualificação do pessoal envolvido e o aproveitamento do grande potencial de utilização para o turismo, como produtos de oferta (BRAMBATTI, 2002, p.7).

No tocante ao processo de planejamento turístico e às áreas turísticas, Bullón (1990), em sua obra "Planificación Del Espacio Turístico", assim descreve:

Las áreas turísticas deben estar dotadas de atractivos turísticos contiguos, en número también menor que los de la zona y lo mismo que ellas necesitan una infraestructura de 


\begin{abstract}
transporte y comunicación que relacione entre sí a todos los elementos turísticos que la integran. Para que puedan funcionar como un subsistema requieren la presencia mínima de un centro turístico y si su infraestructura y dotación de equipamiento y servicios es insuficiente, deben registrarse como potenciales (BULLÓN, 1990, p.69).
\end{abstract}

Assim, o Vale desenvolve as atividades turísticas, com um centro de informações cujo objetivo é orientar o fluxo de turistas no sentido de conhecer as belezas da paisagem, seus vinhedos e atrativos, bem como seus estabelecimentos vinícolas, que elaboram vinhos e espumantes com a logomarca D.O. - Denominação de Origem Vale dos Vinhedos.

Reforça a ideia do planejamento do turismo o que Fávero (2006) estabelece:

O planejamento serve para auxiliar a determinar quem perde ou ganha no processo de desenvolvimento turístico, além de ajudar a contribuir para formas mais sustentáveis de turismo, nas quais se vê o equilíbrio das metas econômicas, ambientais e sociais, que geram resultados mais justos às partes interessadas, o que significa não apenas os incorporadores, o setor turístico e o turista, mas também a comunidade maior cujo destino está sendo consumido (FÁVERO, 2006, p. 62).

Com relação ao desenvolvimento do enoturismo, e a venda dos produtos locais, Valduga (2007) enfatiza os seguintes impactos positivos:

a) surgimento de novos negócios; b) surgimento de cursos que oferecem capacitação técnica aos profissionais; c) incremento e diversificação de renda; d) vinculação de pessoas ao território; e) promoção de uma dinâmica social mediante uma cultura organizacional voltada para o desenvolvimento local (VALDUGA, 2007, p. 99).

As bases teóricas dos autores citados contribuíram para fundamentar o estudo e foram relevantes para dar embasamento à presente pesquisa, que buscou analisar e identificar fatores que interferem no desenvolvimento e planejamento do turismo no espaço rural do Vale dos Vinhedos.

\title{
3 METODOLOGIA
}

Os procedimentos metodológicos adotados no presente estudo, através de uma abordagem qualitativa, iniciaram com um levantamento da bibliografia relacionada ao tema e após, com leituras sobre conceitos e informações pertinentes e dados existentes na APROVALE, publicações de artigos e dissertações de pesquisadores sobre o turismo do Vale dos Vinhedos. 


\section{Gestãoe Desenvolvimento}

De acordo com Barroso (2012):

Uma análise dos instrumentos de pesquisa mostra-se interessante para a escolha do instrumento que se encaixa de maneira mais apropriada em relação ao estudo a ser executado, fazendo com que o pesquisador possa realizar a opção correta para o desenvolvimento do seu trabalho, podendo identificar quais os possíveis fatores positivos e negativos inerentes ao instrumento de pesquisa a ser utilizado (BARROSO, 2012).

Referindo-se à pesquisa bibliográfica, Dencker (2000, p.125) afirma que:

Toda pesquisa requer uma fase preliminar de levantamento e revisão da literatura existente para elaboração conceitual e definição dos marcos teóricos. A pesquisa bibliográfica permite um grau de amplitude maior, economia de tempo e possibilita o levantamento de dados históricos. O pesquisador deve analisar a forma como foram colhidos os dados e confrontá-los com outras fontes, a fim de reduzir a possibilidade de erro (DENCKER, 2000, p.125).

Um dos instrumentos utilizados foi a entrevista, com a finalidade de obter informações sobre os fatores determinantes do desenvolvimento da vitivinicultura e do enoturismo, bem como identificar problemas existentes que necessitam de ações estratégicas urgentes por parte da administração pública e dos empreendedores do turismo do Vale dos Vinhedos. As entrevistas foram realizadas com produtores rurais, proprietários de vinícolas e representantes da Associação do Vale dos Vinhedos.

Para Dencker (2000, p.138), "a entrevista é uma comunicação verbal entre duas ou mais pessoas com um grau de construção previamente definido, cuja finalidade é a obtenção de informações de pesquisa”. Outro instrumento de pesquisa utilizado foi a observação participante e visitas a proprietários rurais, empreendedores e responsáveis pela atividade turística do Vale dos Vinhedos.

Referindo-se aos tipos de pesquisa, Köche (2013) conceitua a pesquisa bibliográfica como:

A que se desenvolve tentando explicar um problema, utilizando o conhecimento disponível a partir das teorias publicadas em livros ou obras congêneres. Na pesquisa bibliográfica o investigador irá levantar o conhecimento disponível na área, identificando as teorias produzidas, analisando-as e avaliando sua contribuição para auxiliar a compreender ou explicar o problema objeto da investigação. O objetivo da pesquisa bibliográfica, portanto, é o de conhecer e analisar as principais contribuições teóricas existentes sobre um determinado tema ou problema, tornando-se um instrumento indispensável para qualquer tipo de pesquisa (KÖCHE, 2013, p.122). 
Com esses procedimentos metodológicos, tornou-se possível observar os principais aspectos do desenvolvimento econômico, sociocultural e ambiental, identificando potencialidades do turismo na região do Vale, e observar problemas existentes que exigirão estratégias de solução.

\section{ANÁLISE DE RESULTADOS}

Com a análise das entrevistas, pode-se verificar que há fatores positivos importantes responsáveis pela motivação dos produtores rurais do Vale dos Vinhedos. Entre os apontados estão: o espírito empreendedor dos moradores, a preservação da paisagem, do patrimônio e das tradições culturais, a criação de novos empregos, qualificação dos vinhos, surgimento de agroindústrias, o enoturismo e o desenvolvimento da vitivinicultura, da gastronomia e dos meios de hospedagem, além do Vale dos Vinhedos ser considerado Patrimônio Histórico e Cultural do Rio Grande do Sul.

A partir da análise de sete entrevistas realizadas, com dois produtores rurais, quatro proprietários de estabelecimentos vinícolas e um representante da Associação de Produtores de Vinhos Finos, pôdese verificar mudanças relacionadas ao desenvolvimento turístico, respondendo à seguinte pergunta: Que

\section{mudanças ocorreram no Vale dos Vinhedos a partir da criação da APROVALE (1995)?}

- Entrevistado 1: Denominação de origem do Vale dos Vinhedos, criação de novos empregos, qualificação dos vinhos, surgimento de agroindústrias; criou-se desenvolvimento da vitivinicultura, gastronomia e hotelaria na região.

- Entrevistado 2: Somente benefícios para as grandes empresas vinícolas.

- Entrevistado 3: Graças à APROVALE, hoje, o Vale dos Vinhedos é mundialmente conhecido como uma importante região vitivinícola e enoturística. Possui um calendário de eventos, com o propósito de aproveitar as 4 estações do ano. Está difundindo o enoturismo cada vez mais, através de DVDs, sites sempre atualizados, mapas e folderes. Mas isso não é tudo, penso eu, o Vale espera que os profissionais da área do turismo e do enoturismo, juntamente com os empreendedores e órgãos oficiais, possam incrementar o calendário de eventos do Vale dos Vinhedos.

- Entrevistado 4: O Vale ficou mais conhecido, pois a APROVALE divulga bastante para o País inteiro, trazendo muitos turistas para conhecer o Vale dos Vinhedos.

- Entrevistado 5: Com a Associação, conseguimos divulgar nossas marcas, e serem reconhecidas, em pouco espaço de tempo, a nível nacional e internacional.

- Entrevistado 6: Existiu grande desenvolvimento e valorização da região e do vinho aqui produzido.

- Entrevistado 7: As principais mudanças estão relacionadas ao estímulo ao empreendedorismo, com o surgimento de muitas iniciativas, em todas as áreas, vinculadas à vitivinicultura e ao 
enoturismo. Como consequência, temos o crescimento da autoestima de boa parte dos moradores. Hoje, estão muito orgulhosos de seu local de origem. Reflete-se no ambiente, com seus lugares bem cuidados, convidando o visitante e dando melhor qualidade de vida a todos.

As respostas a seguir, dos sete entrevistados, mostram o que os produtores pensam a respeito da questão: 0 enoturismo e a vitivinicultura são uma alternativa econômica para os produtores rurais do

\section{Vale dos Vinhedos?}

- Entrevistado 1: Sim, no futuro poderemos ter enoturismo forte, pois temos muito para crescer. Porém, na vitivinicultura devemos qualificar nossos produtos, talvez até diminuir nossa produtividade por hectare, aumentando a qualidade dos produtos. Para isso, o consumo de vinho deve aumentar, garantindo o sustento dos produtores. As famílias devem, também, diversificar sua produção com outros cultivos, não só na vitivinicultura.

- Entrevistado 2: Foi, mas não é mais. Muitos moradores buscam "livrar-se" do emprego de produtor de uvas, justamente pela renda que é inexpressiva.

- Entrevistado 3: Com certeza, a vitivinicultura, somada ao enoturismo, trouxe grande desenvolvimento ao Vale dos Vinhedos, gerando novas oportunidades de emprego e de agronegócios.

- Entrevistado 4: Sim, com o enoturismo surgiram pequenas vinícolas, favorecendo pequenos produtores, agregando mais valor nas uvas, consequentemente, gerando emprego para as famílias e outros. Também surgiram restaurantes, hotéis, e pousadas que trouxeram investidores e pessoas de fora do Vale. Teve aumento do plantio das uvas de mesa in natura e coberta, dando mais renda para os moradores. Teve aumento na produção de suco de uva e geleias.

- Entrevistado 5: O enoturismo é o que mais cresce no mundo em valores financeiros. Quem frequenta é um público diferenciado, que procura por história, gastronomia, vinhos e bem viver.

- Entrevistado 6: Sim, tem-se mostrado uma alternativa sustentável a longo prazo.

- Entrevistado 7: Ambos são a grande alternativa econômica para os produtores rurais do Vale. Temos necessidade de prepará-los melhor para que tenham condições de enfrentar os avanços tecnológicos da viticultura. No enoturismo, podem ampliar a gama de produtos e serviços a ofertar, ligados à cultura da região.

Os produtores rurais entrevistados, referindo-se a situações que merecem a atenção dos empreendedores do turismo e da administração pública, responderam ao seguinte questionamento: Quais os problemas ou fatores que dificultam ou prejudicam o pleno desenvolvimento do turismo no Vale dos Vinhedos? 
- Entrevistado 1: Limitações de crescimento devido ao plano diretor municipal voltado essencialmente para o turismo, limitando os investimentos em outros setores.

- Entrevistado 2: A falta de conscientização dos moradores em manter o patrimônio, apesar das dificuldades por eles encontradas e o pouco cuidado de cada proprietário em manter as margens da rodovia limpas e organizadas.

- Entrevistado 3: O principal problema, na minha opinião, é falta de estímulo aos produtores de uva que, cada vez mais, abandonam seus parreirais, procuram trabalho na cidade, ou vendem suas propriedades. Podemos destacar as péssimas condições da RST 444, oferecendo grande risco aos moradores locais e visitantes pela falta de estacionamento.

- Entrevistado 4: A estrada ruim, esburacada, pouca sinalização e sem acostamento. Falta de apoio do poder público municipal. Pouco incentivo e valorização para o produtor de uva por parte das indústrias vinícolas. Ter mais opções, mais promoções, receber bem os turistas e ter preços bons.

- Entrevistado 5: Acesso, estradas e sinalização. Especulação imobiliária. O agricultor, produtor de uva e as vinícolas não estão em perfeita harmonia.

- Entrevistado 6: Carga tributária dos vinhos; infraestrutura que compete à gestão pública (estradas, transporte coletivo) e subsídios agrícolas.

- Entrevistado 7: Os problemas maiores estão ligados a questões estruturais: estradas, comunicações e transportes. A não concretização da ciclovia, projetada pelo DAER, com o apoio material da APROVALE, é a grande frustração de muitos empreendedores. A internet e a telefonia celular são de difícil acesso. Existem trechos viários com deficiências na pavimentação e, em alguns casos, inexiste. O transporte coletivo para a comunidade é atendido em caráter precário e, para o turista, não existe. Depende exclusivamente de transporte individual, táxi ou outros serviços (vans).

Surgem, além dos fatores citados nas entrevistas, outras questões para análise e reflexão: o que fazer para que os interesses do crescimento imobiliário não afetem o enoturismo e quais os impactos da atividade turística no zoneamento e uso do solo e na preservação na paisagem atual e ampliação da paisagem vitivinícola do Vale dos Vinhedos?

Os resultados advindos das entrevistas de produtores rurais e proprietários de estabelecimentos vinícolas mostram os fatores mais importantes responsáveis pelo desenvolvimento do turismo do Vale, e que atraem grande número de turistas provenientes de várias regiões do Brasil e de outros países, conforme a figura 2. 
Figura 2 - Consolidação do Fluxo Turístico no Vale dos Vinhedos

\begin{tabular}{|l|}
\hline 2001 - Total: 45.000 Turistas \\
\hline 2002 - Total: 60.000 Turistas \\
\hline 2003 - Total: 82.000 Turistas \\
\hline 2004 - Total: 102.000 Turistas \\
\hline 2005 - Total: 115.737 Turistas \\
\hline 2006 - Total: 105.617 Turistas \\
\hline 2007 - Total: 120.962 Turistas \\
\hline 2008 - Total: 153.779 Turistas \\
\hline 2009 - Total: 182.229 Turistas \\
\hline 2010 - Total: 200.508 Turistas \\
\hline 2011 - Total: 228.579 Turistas \\
\hline 2012 - Total: 248.548 Turistas \\
\hline 2013 - Total: 283.240 Turistas \\
\hline
\end{tabular}

Fonte: Banco de Dados da Aprovale

\section{CONSIDERAÇÕES FINAIS}

Este artigo objetivou identificar os principais fatores que impulsionaram o desenvolvimento econômico, garantindo maior qualidade de vida, valorização dos produtos, maior emprego e renda, constituindo-se uma alternativa econômica para os produtores rurais e empreendedores do turismo do Vale dos Vinhedos.

Nesse sentido, pode-se afirmar que o sucesso do Vale dos Vinhedos como roteiro turístico dependerá do empreendedorismo dos proprietários de estabelecimentos vinícolas, dos produtores rurais e viticultores, dos habitantes do Vale e sua integração com as lideranças da administração municipal. Acredita-se que, com essa integração, os benefícios, tanto econômicos como culturais, garantirão um desenvolvimento contínuo e sustentável do turismo.

Devido à proposta desta pesquisa exigir mais tempo de execução, não puderam ser desenvolvidos outros aspectos relevantes para o desenvolvimento turístico, como a dimensão ambiental do roteiro e dos processos de elaboração dos vinhos e dos atrativos, problemas de infraestrutura, especulação imobiliária, o avanço da área urbana sobre o espaço do turismo rural, as dificuldades na execução de diretrizes comuns para o turismo do Vale dos Vinhedos por parte dos três municípios que a integram, que poderão ser objeto de novos estudos e novas pesquisas.

É preciso que se busque conciliar a necessidade de crescimento com a diminuição de impactos negativos apontados pelos produtores rurais em suas entrevistas.

Os resultados alcançados com este estudo são relevantes e servirão de análise e reflexão por parte da comunidade local, dos poderes públicos e empreendedores para que o turismo, através da vitivinicultura e do enoturismo, continue sendo uma alternativa econômica para os produtores rurais do Vale dos Vinhedos. 


\section{REFERÊNCIAS}

APROVALE. Associação de Produtores de Vinhos Finos do Vale dos Vinhedos. Disponível em: <www.valedosvinhedos.com.br>. Acesso em: 23 jun. 2014.

Associação Brasileira de Normas Técnicas - ABNT. NBR 15401: Meios de hospedagem: Sistema de gestão da sustentabilidade - requisitos. Rio de Janeiro: ABNT, 2006.

BARROSO, André Luís Ruggiero. Instrumentos de pesquisa científica qualitativa: vantagens, limitações, fidedignidade e confiabilidade. Revista Digital, Buenos Aires, a. 17, n.172, sep. 2012. Disponível em: <http:// www.efdeportes.com/efd172/instrumentos-de-pesquisa-cientifica-qualitativa.htm>. Acesso em: 23 jun. 2014.

BENI, Mario Carlos. Análise Estrutural do Turismo. 2. ed. São Paulo: Editora SENAC São Paulo, 1998.

BENTO GONÇALVES. Lei Complementar n 103, 26 out. 2006. Institui o novo Plano Diretor de Desenvolvimento Integrado do Município. Disponível em: <http://www.lexml.gov.br/urn/urn:lex:br;rio.grande.sul;bento. goncalves:municipal:lei.complementar:2006-10-26;103>. Acesso em: 10 jun. 2013.

BRAMBATTI, Luiz E. (Org.). Roteiros de Turismo e Patrimônio Histórico. Porto Alegre: EST Edições, 2002.

BRASIL. Lei Federal nº 10.257, de 10 jul. 2001. Estatuto da Cidade e Legislação Correlata. 2. ed., atual. Brasília: Senado Federal, Subsecretaria de Edições Técnicas, 2002. 80 p.

BULLÓN, Roberto C. Planificación Del Espacio Turístico. 4. Ed. México: Trillas, 2006, p. 69. Disponível em: <http://www.unich.edu.mx/wp-content/uploads/2014/01/PLANIFICACION-DEL-ESPACIO-TURISTICO.pdf>. Acesso em: 23 jun. 2014

DE PARIS, Assunta. (Org.). Memórias: Bento Gonçalves - 109 anos. Prefeitura Municipal de Bento Gonçalves: Arquivo Histórico Municipal, 1999.

DIAS, Reinaldo. Turismo Sustentável e Meio Ambiente. Reinaldo Dias. 1. ed. São Paulo: Atlas, 2008.

FALCADE, Ivanira. Indicações Geográficas, o caso da região com indicação de procedência Vale

dos Vinhedos. Dissertação (Mestrado em Programa de Pós-Graduação em Geografia) - Universidade Federal do Rio Grande do Sul, RS, 2005. Disponível em: <http://www.lume.ufrgs.br/bitstream/handle/10183/7364/000498867.pdf?sequence=1>. Acesso em: 23 jun. 2014

FÁVERO, Ivane Maria Remus. Políticas de Turismo: Planejamento na região uva e vinho. Caxias do Sul/RS: Educs, 2006. 
FERNÁDEZ, Maria Gabriela Vázquez. Indicações Geográficas e seus impactos no desenvolvimento dos pequenos produtores do Vale dos Vinhedos - RS. Dissertação (Mestrado em Programa de Pós-Graduação em Agronegócios) - Universidade de Brasília, DF, 2012.

IGNARRA, Luiz Renato. Fundamentos do Turismo. São Paulo: Pioneira Thomson Learning, 2001.

KÖCHE, José Carlos. Fundamentos de Metodologia Científica: Teoria da ciência e iniciação à pesquisa. 32. ed. Petrópolis, RJ: Vozes, 2013.

LUCHESE, Terciane Ângela. Os roteiros turísticos de Bento Gonçalves. In. BRAMBATTI, Luiz E. (Org.). Roteiros de Turismo e Patrimônio Histórico. Porto Alegre: EST Edições, 2002.

RUSCHMANN, Dóris van de Meene. Turismo e Planejamento Sustentável: A proteção do meio ambiente. Campinas, SP: Papirus, 1997. Coleção Turismo.

SANTOS, Eurico de Oliveira. $\mathbf{0}$ agroturismo e o turismo rural em propriedades da metade sul do Estado do Rio Grande do Sul. Porto Alegre: Pallotti, 2004.

UBALDO, Edson. Vinho um presente dos deuses. Letras contemporâneas, 1999.

VALDUGA, Vander. 0 processo de desenvolvimento do enoturismo no Vale dos Vinhedos. Dissertação (Mestrado em Programa de Pós-Graduação em Turismo) - Universidade de Caxias do Sul, Rio Grande do Sul, 2007. Disponível em: <https://repositorio.ucs.br/jspui/bitstream/11338/193/1/Dissertacao\%20Vander\%20 Valduga.pdf>. Acesso em: 23 jun. 2014.

WANDERLEY, M.D.N.B. A emergência de uma nova ruralidade nas sociedades modernas avançadas: o "rural" como espaço singular e ator coletivo. Estudos Sociedade e Agricultura. n. 15, p. 87-145, 15 out. 2000. Disponível em: <<http://bibliotecavirtual.clacso.org.ar/ar/libros/brasil/cpda/estudos/quinze/nazare15.htm>. Acesso em: 23 jun. 2014. 